\title{
Estado do Conhecimento em Administração da Educação: Uma análise dos artigos publicados em periódicos nacionais 1982-2000
}

\author{
Marta Luz Sisson de Castro \\ Flávia Obino Corrêa Werle
}

\section{Resumo}

O texto apresenta o Banco de Dados "Produção do conhecimento na área de administração da educação: periódicos nacionais, 1982-2000", seus objetivos e características e o analisa na sua integralidade. Compara sua fase inicial 1982-1994 com a fase final 19952000 e com o Banco na sua totalidade compreendendo o período 1982 a 2000. Neste Banco estão classificados 3573 artigos de cinqüenta e quatro periódicos nacionais classificados com um thesaurus de cinqüenta e nove palavras-chave Inicialmente foram utilizados os títulos dos artigos para o processo de classificação na segunda fase foram incluídos os resumos. As palavras-chave com maior freqüência no Banco com um todo foram Administração do Ensino Superior, Administração da Educação e Determinantes do Contexto, Política Educacional, Políticas Públicas, Administração Educacional Escolar, Formação e Desenvolvimento Profissional, Administração e História, Poder, Legislação, Avaliação da Edu- cação. Na parte final deste texto refletiu-se acerca das implicações teóricas da classificação da produção em palavras chave e sua distribuição temporal e em periódicos. Foi possível observar que o processo analítico e classificatório de artigos, indicou uma abrangência ampla e uma complexidade inerente à área. Administração da educação é ao mesmo tempo específica e geral, permite vários tipos de segmentação e em seus processos interativos se aproxima de sistemas adaptativos complexos.

Palavras-chave: Artigos publicados. Periódicos nacionais. Administração da educação. Banco de dados.

Um estado da arte ou do conhecimento é uma análise da produção acadêmica em uma determinada área que permite reconhecer e identificar o conhecimento produzido, as áreas de tensão e possíveis avanços na compreensão do tema em estudo. Luna ( 2002, p. 82- 
83) diz que a construção de um estado da arte tem como objetivo a descrição

[...] do estado atual de uma determinada área de pesquisa: o que já se sabe, quais as principais lacunas, onde se encontram os principais entraves teóricos e/ ou metodológicos. Entre as muitas razões que tornam importantes estudos com esse objetivo, devese lembrar que eles constituem uma excelente fonte de atualização para pesquisadores fora da área na qual se realiza o estudo na medida em que condensam os pontos importantes do problema em questão.

Nóbrega-Therrien e Therrien (2004, p. 622) apresentam um conceito um pouco mais restrito do estado da arte considerando que seus objetivos são "mapear e discutir uma certa produção científica/acadêmica em determinado campo do conhecimento" e se caracteriza por ser um "levantamento bibliográfico em resumos e catálogos de fontes relacionadas a um campo de investigação." Distinguem o estado da arte do estado da questão e da revisão da literatura. Para estes autores (NÓBREGA-THERRIEN; THERRIEN, 2004, p. 622 ) a revisão da literatura tem como objetivo "desenvolver a base teórica de sustentação/análise do estudo, ou seja a definição das categorias centrais da investigação" e o estado da questão visa delimitar o objeto específico de interesse do pesquisador e identificar e definir as "categorias centrais da abordagem teórica metodológica."

A distinção proposta por Nóbrega-Therrien e Therrien (2004) pode ser útil na medida em que diferentes fontes de conhecimento estão organizadas e disponibilizadas em diversas formas e meios, e talvez permita com esta divisão lidar um pouco melhor com a tarefa de fundamentação empírica e teórica de um trabalho de pesquisa quando existe um número muito grande de informações disponíveis. Mas o trabalho básica de identificar o que se sabe, o que precisamos buscar, quais são os temas em tensão em debate, continua existindo como tarefa geral. Assim no estado da arte, estamos considerando a construção de um mapeamento da produção acadêmica usando tanto os resumos e catálogos, como teses, dissertações, relatórios de pesquisa, estudos teóricos e obras publicadas sobre o tema.

Ferreira (2002, p. 258) enfatiza talvez através da citação de vários estudos realizados no Brasil, nos últimos anos, a compreensão local do termo estado da arte no contexto acadêmico brasileiro.

Definidas como de caráter bibliográfico, elas parecem trazer em comum o desafio de mapear e de discutir uma produção acadêmica em diferentes campos do conhecimento, tentando responder que aspectos e dimensões vêm sendo destacados e privilegiados em diferentes épocas e lugares, de que formas e em que condições têm sido produzidas certas dissertações de mestrado, teses de doutorado, publicações em periódicos e comunicações em anais de congressos e seminários. Também são reconhecidas por realizarem uma metodologia de caráter inventariante e descritivo da produção acadêmica e científica sobre o tema que busca investigar.

Banco de Dados "Produção do conhecimento na área de administração da educação: periódicos nacionais, 1982-2000", foi desenvolvido com o objetivo de mapear a pro- 
dução publicada por periódicos brasileiros em Administração da Educação, buscando dar conta da ampliação dos debates acerca da validade e natureza do conhecimento na área. Representa um esforço único no contexto educacional brasileiro, pois inexistem bancos de dados sobre publicações nacionais na área educacional de uma forma abrangente. Os estudos existentes trabalham com um periódico específico, como Pereira (2004) com a produção apresentada em determinado evento, como Catani e Faria (2002), Fávero (2002) e Brzezinski (2001) que analisam grupos de trabalho da ANPED ou trabalham com a produção dos programas de pós-graduação em Educação, como os estudos realizados pela Associação Nacional de Política e Administração da Educação (ANPAE), com Wittmann e Gracindo $(1999,2001)$ utilizando os resumos das teses e dissertações disponíveis. Um levantamento dos periódicos da área de educação de uma forma consistente abrangendo um número significativo de publicações e cobrindo um período de quase vinte anos, se constitui num recurso singular e se consolida por não ter similar no contexto educacional brasileiro.

A metodologia utilizada para a construção do Banco de Dados foi sendo desenvolvida pelas pesquisadoras e aperfeiçoada ao longo dos anos. Inicialmente foram utilizados somente os títulos dos artigos, classificados a partir da cópia xerográfica do sumário dos periódicos educacionais disponíveis nas bibliotecas da Pontifícia Universidade Católica do Rio Grande do Sul, da Universidade do Vale do Rio dos Sinos e da Universidade Federal do Rio Grande do Sul. As pesquisadoras tentaram utilizar thesaurus disponíveis na área educacional, mas a construção de um thesaurus próprio foi o caminho que se revelou necessário e resultou na definição das cinqüenta e nove palavras-chave.
Banco de Dados se desenvolveu em duas fases. A fase inicial analisou artigos publicados em periódicos nacionais no período de 1982-1994 e produziu além do Banco de Dados uma bibliografia anotada. Na segunda fase o processo de classificação se aprimorou, pois além do título, foram incluídos os resumos e novos periódicos classificados pelo Qualis como $\mathrm{Na}$ cional $A$ e excluídos alguns periódicos da listagem anterior.

No seu conjunto, o Banco de Dados classificou 3.573 artigos de cinqüenta e quatro periódicos com pelo menos três palavras-chave. $\bigcirc$ Banco de Dados permite a pesquisa utilizando critérios como data, periódico, palavras-chave, autor. $\bigcirc$ mesmo se constitui numa fonte de informações para pesquisadores da área de administração educacional e poderá auxiliar pós-graduandos na definição de seus objetivos de pesquisa. $\bigcirc$ estudo que realizamos com o Banco de Dados pode ser considerado um estado da arte no sentido proposto por Ferreira (2002) e Nóbrega-Therrien e Therrien (2004), mas, como diz Werle (2001, p. 60)

Um Banco de Dados é uma forma de ação, de pesquisa e de produção de conhecimento. Ao capturar em si documentos, manifesta uma forma de conhecer e modificar, transformar o objeto, institui um processo que transforma os documentos (estrutura, códigos, relacionamentos, níveis).

A distribuição das palavras-chave é um indicador do quanto estes temas foram discutidos no meio acadêmico educacional no período. Análises anteriores ${ }^{1}$, a respeito Castro e Werle (1999) mostraram uma predominância de temas referentes ao ensino superior e às 
políticas, evidenciando uma falta de trabalhos e estudos sobre a realidade da administração das escolas e demais instituições de ensino. Outras análises realizadas sobre palavras-chave e sua distribuição temporal foram capazes de identificar temas emergentes que refletiam questões da história e realidade vivida, a distribuição de palavras-chave por periódicos. Castro e Werle (2000) mostraram o interesse e a caracterização editorial das revistas.

Esta distribuição temática e temporal possibilita o relacionamento com o momento histórico abrangido e com outras produções temáticas significativas. Cada um dos passos pode ser realizado independentemente e permite diferentes tipos de olhares sobre a produção acadêmica em Administração Educacional.

As autoras já realizaram diferentes tipos de análise ${ }^{2}$, fazendo em alguns casos leitura completa dos artigos cadastrados e examinados como em Werle e Castro (2000) onde se estudou a produção sobre a América Latina, ou ainda relacionaram o estudo de duas palavras-chave com uma revisão da literatura sobre o tema do abandono escolar em Werle e Castro (2003). Foram também realizados estudos destacando e caracterizando os periódicos (CASTRO; WERLE, 2000), ou seja, o Banco de Dados permite a identificação de artigos relacionados que podem ser estudados de diferentes maneiras. Isto, entretanto, não caracterizaria um estado da arte no sentido proposto por Ferreira (2002). Os estudos realizados pelas autoras validam o Banco de Dados como um instrumento útil para a reconstrução da produção acadêmica na área de Administração da Educação de uma forma diversificada e completa.

\section{Caracterização do Banco de Dados}

Neste texto será apresentada a distribuição das palavras-chave no Banco de Dados 1982-2000, em suas duas fases de desenvolvimento de 1982- 1994 e de 1995 2000. Serão analisados os periódicos que mais contribuíram para o Banco de Dados na sua integralidade. $E$, num segundo momento serão discutidas as implicações destes dados para uma compreensão teórica da área de Administração da Educação.

As palavras-chave organizadas por ordem de freqüência no Banco de Dados considerado em sua integralidade são apresentadas na Tabela 1. Apesar de o Banco de Dados ter um thesaurus com 59 palavras-chave, nem todas contribuem com 0 mesmo número de artigos. Assim, Administração do Ensino Superior classificou 529 artigos enquanto Movimento Estudantil teve apenas dezessete artigos classificados, exemplificam os dois extremos. Trinta e uma palavras-chave pouco mais da metade das cinqüenta e nove abrangem $80 \%$ dos artigos cadastrados, indicando concentração desigual de focos temáticos.

\footnotetext{
1 Estudos realizados com o Banco de Dados na sua fase inicial, 1982-1994, consideraram as palavras-chave mais freqüentes no Banco como um todo, outros estudos consideraram os periódicos que mais contribuíram para o Banco de Dados, foram realizadas também análises considerando os resumos, e ou/ os artigos classificados na sua íntegra.

${ }^{2}$ As autoras desenvolveram uma metodologia para a construção de um artigo a partir da análise de uma palavra-chave do Banco de Dados que segue os seguintes passos: 1.Pesquisa e listagem da palavra-chave. 2. Frequência da palavra-chave. 3. Identificação da área temática (utilizando títulos e resumos) agrupados por sub-temas, ano e periódico. 4. Análise descritivo-interpretativa da distribuição temporal dos sub-temas. 5. Análise dos resumos. 6. Análise dos periódicos. 6. Conclusão considerando o perfil da palavra-chave a e a validação do Banco.
} 


\section{Tabela 1}

\section{Freqüência das palavras-chave no Banco de Dados 1982-2000}

\begin{tabular}{|c|c|c|c|}
\hline Palavra-chave & Freqüência & $\% *$ & Cum. \\
\hline Administração do Ensino Superior & 529 & 6,55 & 6,55 \\
\hline Administração da Educação e Determinantes do Contexto & 412 & 5,10 & 11,65 \\
\hline Política Educacional & 391 & 4,83 & 16,48 \\
\hline Políticas Públicas & 325 & 4,02 & 20,50 \\
\hline Administração Educacional Escolar & 310 & 3,84 & 24,34 \\
\hline Formação e Desenvolvimento Profissional & 301 & 3,73 & 28,07 \\
\hline Administração e História & 241 & 3,00 & 31,07 \\
\hline Poder & 223 & 2,73 & 33,80 \\
\hline Legislação & 210 & 2,60 & 36,40 \\
\hline Avaliação da Educação & 201 & 2,50 & 38,90 \\
\hline Administração Comparada & 191 & 2,36 & 41,26 \\
\hline Educação e Democratização & 186 & 2,30 & 43,56 \\
\hline Qualidade da Educação & 183 & 2,27 & 45,83 \\
\hline Administração em Nível Macropolítico & 182 & 2,25 & 48,08 \\
\hline Administração da Educação e Teoria & 180 & 2,23 & 50,31 \\
\hline Gestão e Cultura & 175 & 2,17 & 52,48 \\
\hline Ensino Fundamental & 169 & 2,10 & 54,58 \\
\hline Conhecimento e Ação Administrativa & 167 & 2,07 & 56,65 \\
\hline Administração de Sistemas Educacionais & 163 & 2,01 & 58,66 \\
\hline Administração da Educação e Inovações Tecnológicas & 153 & 1,90 & 60,56 \\
\hline Cidadania & 152 & 1,88 & 62,44 \\
\hline Administração e Organização Didático Pedagógica na Escola & 151 & 1,87 & 64,31 \\
\hline Educação e Profissionalização do Educador & 151 & 1,87 & 66,18 \\
\hline Temas Organizacionais & 151 & 1,87 & 68,05 \\
\hline Educação e Economia & 147 & 1,81 & 69,86 \\
\hline Administração Participativa & 144 & 1,78 & 71,64 \\
\hline Educação Popular & 141 & 1,74 & 73,38 \\
\hline Descentralização-Municipalização & 137 & 1,69 & 75,07 \\
\hline Mudanças Sociais - Educacionais & 137 & 1,69 & 76,76 \\
\hline Direitos da Criança & 133 & 1,64 & 78,40 \\
\hline
\end{tabular}




\section{Tabela 1 (continuação)}

\begin{tabular}{|c|c|c|c|}
\hline Igualdade de Oportunidades & 130 & 1,60 & 80,00 \\
\hline Administração de Níveis e Tipos Diferentes de Ensino & 126 & 1,56 & 81,56 \\
\hline Financiamento da Educação & 122 & 1,50 & 82,06 \\
\hline Planejamento Educacional & 111 & 1,37 & 84,43 \\
\hline Relações Público e Privado & 110 & 1,36 & 85,79 \\
\hline Relação Sociedade e Educação & 106 & 1,31 & 87,10 \\
\hline Gestão Democrática & 95 & 1,17 & 88,27 \\
\hline Formação e Desenvolvimento do Especialista em Educação & 87 & 1,08 & 89,35 \\
\hline Ensino Médio & 72 & 0,90 & 90,25 \\
\hline Avaliação Institucional & 70 & 0,86 & 91,11 \\
\hline Raça & 64 & 0,80 & 91,91 \\
\hline Autonomia Administrativa & 58 & 0,72 & 92,63 \\
\hline Administração Pública & 56 & 0,70 & 93,33 \\
\hline Violência, Drogas e Disciplina & 56 & 0,70 & 94,03 \\
\hline Ensino Rural & 43 & 0,53 & 94,56 \\
\hline Planejamento Participativo & 43 & 0,53 & 95,09 \\
\hline Curso de Pedagogia & 38 & 0,47 & 95,56 \\
\hline Administração de Recursos Humanos & 37 & 0,46 & 96,02 \\
\hline Gênero e Educação & 35 & 0,43 & 96,45 \\
\hline Movimento Docente & 35 & 0,43 & 96,88 \\
\hline Administração da Pós-Graduação & 34 & 0,42 & 97,30 \\
\hline Burocratização Administrativa & 34 & 0,42 & 97,72 \\
\hline Educação Infantil & 33 & 0,41 & 98,13 \\
\hline Avaliação de Desempenho & 32 & 0,40 & 98,53 \\
\hline Eleição & 30 & 0,37 & 98,90 \\
\hline Relação Escola-Comunidade & 29 & 0,36 & 99,26 \\
\hline Administração Escolar e Tempo & 25 & 0,31 & 99,57 \\
\hline Integração Universidade - Escola & 18 & 0,22 & 99,79 \\
\hline Movimento Estudantil & 17 & 0,21 & 100,00 \\
\hline Soma & \multicolumn{3}{|l|}{8082} \\
\hline
\end{tabular}

Fonte: Castro e Werle (2002).

* Favor observar que a freqüência que está sendo considerada nesta coluna refere-se as 8.082 classificações realizadas (cada artigo poderia ser classificado em até três palavras-chave), e que o percentual sobre o Banco de Dados deve ser calculado sobre o número total de artigos cadastrados 3.573. 
Como pode ser observado na Tabela 1, as dez palavras-chave com maior freqüência foram Administração do Ensino Superior, Administração da Educação e Determinantes do Contexto, Política Educacional, Políticas Públicas, Administração Educacional Escolar, Formação e Desenvolvimento Profissional, Administração e História, Poder, Legislação e Avaliação da Educação. Estas dez palavras-chave representam 38.79\% das classificações realizadas.

\section{Fase Inicial do Banco de Dados 1982-1994}

Comparando os resultados totais do Banco de Dados como um todo com os de sua $1^{a}$ fase observamos algumas palavraschave ou temas que surgiram com maior força em período mais recente.

Castro e Werle (1999, p. 130) estudando - Banco de Dados na sua fase inicial identificaram as dez palavras-chave com maior freqüência. Administração do Ensino Superior, Administração da Educação e Determinantes do Contexto, Políticas Públicas, Política Educacional, Administração Educacional Escolar, Legislação, Educação e Democratização, Administração e História, Administração em Nível Macro Político, Formação e Desenvolvimento Profissional foram as palavras com maior freqüência. As palavras-chave Poder, Formação e Desenvolvimento Profissional e Avaliação da Educação se destacam na versão completa do Banco de Dados até o ano 2000, indicando, portanto, mudanças de foco.

\section{Tabela 2}

Freqüência das palavras-chave no Banco de Dados 1982-1994

\begin{tabular}{|l|c|c|c|}
\hline Palavra-chave & Freqüência & \%* & \multicolumn{1}{|c|}{ Cum. } \\
\hline Administração do Ensino Superior & 362 & 7,39 & 7,39 \\
\hline Administração da Educação e Determinantes do Contexto & 252 & 5,15 & 12,54 \\
\hline Política Educacional & 248 & 5,07 & 17,61 \\
\hline Políticas Públicas & 238 & 4,86 & 22,47 \\
\hline Administração Educacional Escolar & 222 & 4,53 & 27,00 \\
\hline Legislação & 138 & 2,82 & 29,82 \\
\hline Educação e Democratização & 136 & 2,78 & 32,60 \\
\hline Administração e História & 132 & 2,70 & 35,29 \\
\hline Administração em Nível Macropolítico & 130 & 2,66 & 37,95 \\
\hline Formação e Desenvolvimento Profissional & 124 & 2,53 & 40,48 \\
\hline Poder & 123 & 2,51 & 42,99 \\
\hline Administração da Educação e Teoria & 114 & 2,33 & 45,32 \\
\hline Administração Comparada & 113 & 2,31 & 47,63 \\
\hline Qualidade da Educação & 113 & 2,31 & 49,94 \\
\hline Temas Organizacionais & 109 & 2,23 & 52,17 \\
\hline Descentralização - Municipalização & 109 & 2,23 & 54,39 \\
\hline Avaliação da Educação & 104 & 2,12 & 56,52 \\
\hline Administração de Sistemas Educacionais & 98 & 2,00 & 58,52 \\
\hline Relaçães Público e Privado & 97 & 1,98 & 60,50 \\
\hline \hline
\end{tabular}




\section{Tabela 2 (continuação)}

\begin{tabular}{|c|c|c|c|}
\hline Educação Popular & 96 & 1,96 & 62,46 \\
\hline Administração Participativa & 92 & 1,88 & 64,34 \\
\hline Administração e Organização Didático-Pedagógica na Escola & 91 & 1,86 & 66,20 \\
\hline Educação e Profissionalização do Educador & 91 & 1,86 & 68,06 \\
\hline Financiamento da Educação & 91 & 1,86 & 69,91 \\
\hline Administração da Educação e Inovações Tecnológicas & 83 & 1,70 & 71,61 \\
\hline Conhecimento e Ação Administrativa & 80 & 1,63 & 73,24 \\
\hline Direitos da Criança & 79 & 1,61 & 74,86 \\
\hline Educação e Economia & 79 & 1,61 & 76,47 \\
\hline Mudanças Sociais - Educacionais & 77 & 1,57 & 78,04 \\
\hline Planejamento Educacional & 77 & 1,57 & 79,62 \\
\hline Formação e Desenvolvimento do Especialista em Educação & 76 & 1,55 & 81,17 \\
\hline Ensino Fundamental & 74 & 1,51 & 82,68 \\
\hline Relação Sociedade e Educação & 69 & 1,41 & 84,09 \\
\hline Administração de Níveis e Tipos Diferentes de Ensino & 65 & 1,33 & 85,42 \\
\hline Gestão Democrática & 60 & 1,23 & 86,64 \\
\hline Gestão e Cultura & 60 & 1,23 & 87,87 \\
\hline Cidadania & 47 & 0,96 & 88,83 \\
\hline Igualdade de Oportunidades & 43 & 0,88 & 89,71 \\
\hline Autonomia Administrativa & 39 & 0,80 & 90,50 \\
\hline Ensino Médio & 37 & 0,76 & 91,26 \\
\hline Raça & 36 & 0,74 & 91,99 \\
\hline Ensino Rural & 35 & 0,71 & 92,71 \\
\hline Administração Pública & 34 & 0,69 & 93,40 \\
\hline Administração de Recursos Humanos & 30 & 0,61 & 94,02 \\
\hline Burocratização Administrativa & 27 & 0,55 & 94,57 \\
\hline Avaliação Institucional & 26 & 0,53 & 95,10 \\
\hline Movimento Docente & 24 & 0,49 & 95,59 \\
\hline Eleição & 23 & 0,47 & 96,06 \\
\hline Relação Escola-Comunidade & 23 & 0,47 & 96,53 \\
\hline Violência, Drogas e Disciplina & 23 & 0,47 & 97,00 \\
\hline Administração da Pós-Graduação & 22 & 0,45 & 97,45 \\
\hline Planejamento Participativo & 20 & 0,41 & 97,86 \\
\hline Avaliação de Desempenho & 16 & 0,33 & 98,18 \\
\hline Curso de Pedagogia & 16 & 0,33 & 98,51 \\
\hline Integração Universidade - Escola & 16 & 0,33 & 98,84 \\
\hline Educação Infantil & 16 & 0,33 & 99,16 \\
\hline Administração Escolar e Tempo & 14 & 0,29 & 99,45 \\
\hline Gênero e Educação & 14 & 0,29 & 99,73 \\
\hline Movimento Estudantil & 13 & 0,27 & 100,00 \\
\hline TOTAL & 4.896 & & \\
\hline
\end{tabular}


As palavras-chave Administração do Ensino Superior, Administração da Educação e Determinantes do Contexto, Política Educacional, Políticas Públicas, Administração Educacional Escolar se mantém nas diferentes fases entre as dez mais freqüentes indicando que estes temas tem sido privilegiados nas publicações nacionais. A ênfase no Ensino Superior pode indicar uma incapacidade da academia em avançar para além de seu próprio círculo de referência e considerar válido aquilo que afeta diretamente sua prática, a publicação sobre outros tipos de ensino e temas representaria um esforço extra para buscar e pesquisar outros níveis e instituições. A predominância de Políticas Educacionais e Políticas Públicas indica que a visão macro se sobrepõe sobre as análises micro que lançariam um olhar mais detalhado, mais próximo sobre a instituição escolar. A emergência de novas palavras-chave como Legislação está certamente associado à discussão que antecedeu a promulgação da Lei de Diretrizes e Bases de 1996 e aos debates posteriores relativos a sua regulamentação e implementação. $\bigcirc$ destaque da palavra-chave Poder pode ser um reconhecimento da dimensão política e de poder subjacente às atividades educacionais, refletindo também a luta pela defesa da educação no país.

O aumento de publicações sobre o tema Avaliação da Educação certamente exprime a onda de avaliações que tem se instalado na educação na última década desde o SAEB até o Provão e outras modalidades de avaliação do sistema. Novas formas de acom- panhamento do ensino superior têm suscitado debate sobre a validade e usos destes instrumentos e conseqüentemente gerou publicações sobre esta temática.

A ênfase em Formação e Desenvolvimento Profissional indica a polêmica sobre a formação do educador no contexto nacional, a criação dos Institutos Superiores de Educação, e novas formas institucionais. As publicações de certa forma documentam o processo de formação de professores ocorrido e a constante necessidade de repensar e atualizar a formação e o desenvolvimento profissional dos educadores.

\section{$2^{a}$ Fase do Banco de Dados: 1994-2000}

A $2^{\circ}$ Fase contemplou publicações em periódicos relativas ao período 1994-2000 e se caracterizou por um processo mais refinado de classificação utilizando além dos títulos, os resumos dos artigos. Registramos neste período significativo aumento no número de publicações em periódicos, o que pode ser avaliado pela comparação com o total de artigos publicados em período anterior.

Como pode ser observado na Tabela 1, foram realizadas 8082 classificações no Banco de Dados como um todo e 3105 no período de seis anos referente a última fase de desenvolvimento o que corresponde a $39.21 \%$ do total. Realmente, parece ter ocorrido uma aceleração no número de publicações nacionais nos últimos tempos na área educacional. 


\section{Tabela 3}

\section{Distribuição das palavras-chave no Banco de Dados por ordem de freqüência no período de 1995-2000}

\begin{tabular}{|l|c|c|}
\hline Palaura-Chave & Freqüência & $\begin{array}{c}\text { Representação } \\
\text { no Total }\end{array}$ \\
\hline 01. Formação e Desenvolvimento Profissional & 175 & $4,89 \%$ \\
\hline 02. Administração do Ensino Superior & 167 & $4,67 \%$ \\
\hline 03. Administração da Educação e Determinantes do Contexto & 160 & $4,47 \%$ \\
\hline 04. Política Educacional & 139 & $3,89 \%$ \\
\hline 05. Gestão e Cultura & 115 & $3,21 \%$ \\
\hline 06. Administração e História & 109 & $3,05 \%$ \\
\hline 07. Cidadania & 102 & $2,84 \%$ \\
\hline 08. Avaliação da Educação & 97 & $2,71 \%$ \\
\hline 09. Ensino Fundamental & 90 & $2,51 \%$ \\
\hline 10. Administração Educacional Escolar & 88 & $2,46 \%$ \\
\hline 10. Poder & 88 & $2,46 \%$ \\
\hline 11. Conhecimento e Ação Administrativa & 87 & $2,43 \%$ \\
\hline 11. Igualdade de Oportunidades & 87 & $2,43 \%$ \\
\hline 12. Políticas Públicas & 82 & $2,29 \%$ \\
\hline 13. Administração Comparada & 77 & $2,15 \%$ \\
\hline 14. Administração da Educação e Inovações Tecnológicas & 70 & $1,95 \%$ \\
\hline 14. Legislação & 70 & $1,95 \%$ \\
\hline 15. Qualidade da Educação & 69 & $1,93 \%$ \\
\hline 16. Educação e Economia & 68 & $1,90 \%$ \\
\hline 17. Administração da Educação e Teoria & 66 & $1,84 \%$ \\
\hline 18. Administração de Sistemas Educacionais & 65 & $1,81 \%$ \\
\hline 19. Administração de Níveis e Tipos Diferentes de Ensino & 61 & $1,70 \%$ \\
\hline 20. Administração e Organização Didático Pedagógica da Escola & 60 & $1,67 \%$ \\
\hline 20. Educação e Profissionalização do Educador & 60 & $1,67 \%$ \\
\hline 20. Mudanças Sociais-Educacionais & 60 & $1,67 \%$ \\
\hline 21. Direitos da Criança & 54 & $1,51 \%$ \\
\hline 22. Administração em Nível Macropolítico & 52 & $1,45 \%$ \\
\hline
\end{tabular}


Estado do Conhecimento em Administração da Educação:

\begin{tabular}{|c|c|c|}
\hline 22. Administração Participativa & 52 & $1,45 \%$ \\
\hline 23. Educação e Democratização & 50 & 1,39 \\
\hline 24. Educação Popular & 45 & $1,25 \%$ \\
\hline 25. Avaliação Institucional & 44 & $1,23 \%$ \\
\hline 26. Temas Organizacionais & 42 & $1,17 \%$ \\
\hline 27. Ensino Médio & 34 & $0,95 \%$ \\
\hline 27. Gestão Democrática & 34 & $0,95 \%$ \\
\hline 27. Planejamento Educacional & 34 & $0,95 \%$ \\
\hline 28. Violência, Drogas e Disciplina & 33 & $0,92 \%$ \\
\hline 29. Financiamento da Educação & 31 & $0,86 \%$ \\
\hline 30. Descentralização-Municipalização & 28 & $0,78 \%$ \\
\hline 31. Raça & 27 & $0,75 \%$ \\
\hline 32. Planejamento Participativo & 23 & $0,64 \%$ \\
\hline 33. Gênero e Educação & 21 & $0,58 \%$ \\
\hline 33. Curso de Pedagogia & 21 & $0,58 \%$ \\
\hline 34. Administração Pública & 20 & $0,55 \%$ \\
\hline 35. Autonomia Administrativa & 19 & $0,53 \%$ \\
\hline 36. Avaliação de Desempenho & 16 & $0,44 \%$ \\
\hline 36. Educação Infantil & 16 & $0,44 \%$ \\
\hline 37. Relações Público Privado & 13 & $0,36 \%$ \\
\hline 38. Administração da Pós-Graduação & 12 & $0,33 \%$ \\
\hline 39. Administração Escolar e Tempo & 11 & $0,30 \%$ \\
\hline 39. Formação de Desenvolvimento do Especialista em Educação & 11 & $0,30 \%$ \\
\hline 39. Movimento Docente & 11 & $0,30 \%$ \\
\hline 40. Ensino Rural & 8 & $0,22 \%$ \\
\hline 41. Administração de Recursos Humanos & 7 & $0,19 \%$ \\
\hline 41. Burocratização Administrativa & 7 & $0,19 \%$ \\
\hline 42. Relação Escola-Comunidade & 6 & $0,16 \%$ \\
\hline 43. Eleição & 5 & $0,16 \%$ \\
\hline 44. Movimento Estudantil & 4 & $0,12 \%$ \\
\hline 45. Integração Universidade-Escola & 2 & $0,06 \%$ \\
\hline TOTAL & 3105 & \\
\hline
\end{tabular}

Fonte: Castro e Werle (2002). 
Como já dissemos anteriormente pode ser observado que algumas palavras- chave se destacaram na fase final do Banco de Dados, quais sejam Formação e Desenvolvimento Profissional, Gestão e Cultura, Cidadania. Avaliação da Educação, Ensino Fundamental e Conhecimento e Ação Administrativa.

Formação e Desenvolvimento Profissional está em sexto lugar em ordem de freqüência no Banco de Dados como um todo com 301 artigos classificados. Na fase final do Banco ela aparece em primeiro lugar com 175 artigos classificados. Essa freqüência indica que mais da metade dos artigos cadastrados com esta palavra-chave foram produzidos recentemente. A incidência identificada revela o interesse que o tema tem levantado nos últimos anos, em relação aos parâmetros estabelecidos pela nova legislação e ao debate em relação ao curso de pedagogia e às necessidades de profissionalização. A distribuição temporal das palavras-chave parece espelhar o debate e os temas prevalentes em determinado período.

Gestão e Cultura aparecem em décimo quinto lugar no Banco como um todo e em quinto lugar na fase mais recente. Indicando que o tema da cultura, e especialmente do multiculturalismo na gestão da educação é atual e faz parte do debate de inclusão do diferente na escola regular. A posição desta palavra-chave no Banco de Dados como um todo parece ter sido determinada pelo maior número de artigos no período 1995-2000 refletindo um maior interesse pela questão cultural. De uma freqüência de 175 artigos classificados com esta temática no conjunto dos dados, 115 artigos foram publicados a partir de 1995, representando $65.71 \%$ do total de artigos classificados com esta temática.

Cidadania aparece em vigésimo primeiro lugar no Banco de Dados como um todo e em sétimo lugar no período final. Esta mudança indica a importância que o tema tem recebido nos últimos anos, dos 149 artigos classificados com esta palavra-chave 102, ou seja $68.41 \%$, foram publicados entre 1995 e 2000 . Esta incidência pode estar relacionada com a discussão do papel da escola e da educação para a formação do cidadão. Provavelmente a ênfase deva-se ao destaque que recebe a palavra-chave Ensino Fundamental que está em décimo sétimo lugar no Banco de Dados como um todo com 164 artigos. Os 90 artigos cadastrados neste período representam mais 54.87\% do total do tema Ensino Fundamental. A discussão do Ensino Fundamental como necessário para a formação e o exercício da cidadania e também como um direito de todo cidadão pode explicar a emergência recente destas duas categorias. O tema Educação e Democratização que aparece em décimo segundo lugar no Banco como um todo com 186 artigos cadastrados e na fase final do Banco passa para o vigésimo terceiro lugar com 50 artigos cadastrados no período pode indicar uma tendência inversa. Pode-se levantar a hipótese que o destaque em Ensino Fundamental e Cidadania sejam a realização da democratização da educação proposta no período anterior. Podem indicar uma discussão mais direta de democratização, com foco na cidadania e na garantia do Ensino Fundamental para todos. 
Avaliação da Educação aparece em décimo lugar com 201 artigos cadastrados, quando se considera o Banco no seu período total de abrangência 1982-2000. $\mathrm{Na}$ fase inicial Avaliação da Educação apresentou 104 artigos e estava em décimo sétimo lugar. $O$ tema assumiu maior destaque na fase final do Banco, onde está em oitavo lugar com 97 artigos cadastrados. Pode-se observar que quase $50 \%$ dos artigos classificados em Avaliação da Educação foram publicados recentemente, indicando que avaliação da educação é um tema ascendente nas publicações nacionais da área educacional e reflete os debates sobre os sistemas de avaliação aplicados ao Ensino Superior, ao Ensino Médio (ENEM) e o SAEB que avalia a educação básica e à Pós-graduação. Se o Banco de Dados estivesse atualizado até 2005 certamente esta palavra-chave teria um destaque crescente nos anos mais recentes, pois a temática da avaliação da educação em termos dos sistemas educacionais é um desenvolvimento universal que tem se aplicado de uma forma mais sistemática no Brasil.

Conhecimento e Ação Administrativa está relacionada à prática e à reflexão sobre a prática e apresenta uma ordem de classificação mais alta na fase final do Banco com a colocação em décimo-primeiro lugar com 87 artigos. $\mathrm{Na}$ análise do total esta palavra-chave estava em décimo-sexto lugar com 167 artigos cadastrados. $O$ fato de metade dos artigos classificados terem sido produzidos no período de 1995-2000 indica um interesse em pensar e refletir a prática administrativa e docente e é uma expressão do debate sobre a Formação e Desenvolvimento Profissional do educador que foi o tema com maior freqüência na fase final do Banco.

\section{Periódicos Nacionais predominantes no Banco de Dados}

Apresentamos os periódicos classificados até 0 décimo-quinto lugar que mais contribuíram para o Banco de Dados: Revista de Administração da USP, Contexto e Educação, Ensaio, Educação e Sociedade, Revista de Educação da AEC, Cadernos de Pesquisa, Revista Brasileira de Política e Administração da Educação, Revista de Administração Pública, Em Aberto, Educação e Realidade, Educação PUCRS, Estudos Leopoldenses, Educação em Revista, Tecnologia Educacional, Revista da Associação Nacional de Educação e Estudos em Avaliação Educacional. 


\section{Tabela 4}

\section{Freqüência de Periódicos Nacionais no Banco de Dados}

\begin{tabular}{|l|c|c|}
\hline Periódico & $\begin{array}{c}\text { No de } \\
\text { artigos }\end{array}$ & Percentagem \\
\hline 01 - Revista de Administração (USP, 1982-2000) & 248 & $7,01 \%$ \\
\hline 02 - Contexto e Educação (UNIJUI, liú́, 1982-2000) & 242 & $6,91 \%$ \\
\hline 03 - Ensaio (Fundação Cesgranrio, 1993-2000) & 210 & $6,00 \%$ \\
\hline 04 - Educação e Sociedade (São Paulo, 1982-2000) & 193 & $5,51 \%$ \\
\hline $\begin{array}{l}05 \text { - Revista da Educação AEC } \\
\text { (Associação de Escolas Católicas, Brasília, 1983-2000) }\end{array}$ & 177 & $5,05 \%$ \\
\hline $\begin{array}{l}\text { 06 - Cadernos de Pesquisa } \\
\text { (Fundação Carlos Chagas, São Paulo, 1982-2000) }\end{array}$ & 174 & $4,97 \%$ \\
\hline $\begin{array}{l}\text { 07 - Revista Brasileira de Administração da Educação (1983-1991) } \\
\text { Revista Brasileira de Política e Administração da Educação }\end{array}$ & 170 & $4,85 \%$ \\
\hline $\begin{array}{l}08 \text { - Revista da Administração Pública } \\
\text { (Fundação Getúlio Vargas, 1982-1999) }\end{array}$ & 159 & $4,54 \%$ \\
\hline 09 - Em Aberto (MEC-INEP, Braślia, 1982-2000) & 157 & $4,48 \%$ \\
\hline 10 - Educação e Realidade (UFRGS, Porto Alegre, 1982-1999) & 98 & $2,77 \%$ \\
\hline 11 - Educação - PUCRS ( Porto Alegre, 1928-2000) & 97 & $2,77 \%$ \\
\hline 12 - Estudos Leopoldenses (Unisinos, São Leopoldo, 1983-2000 & 93 & $2,65 \%$ \\
\hline 13 - Educação em Revista (Belo Horizonte, 1985-2000) & 90 & $2,57 \%$ \\
\hline 14 - Tecnologia Educacional (Rio de Janeiro, 1982-1999) & 90 & $2,57 \%$ \\
\hline $\begin{array}{l}15 \text { - Revista da Associação Nacional de Educação } \\
\text { (ANDE, 1982-1994) }\end{array}$ & 89 & $2,54 \%$ \\
\hline $\begin{array}{l}16 \text { - Estudos em Avaliação Educacional } \\
\text { (Fundação Carlos Chagas, 1990-2000) }\end{array}$ & 86 & $2,45 \%$ \\
\hline Total & $3.573 *$ & $100 \%$ \\
\hline
\end{tabular}

Fonte: Castro e Werle (2002).

* Nesta tabela foram apresentados somente os primeiros dezesseis periódicos do Banco de Dados com maior número de artigos.

A Revista de Administração da USP e a Revista de Administração Pública aparecem como periódicos com foco específico na questão da administração. Outros periódicos são reconhecidos e valorizados na área da educação, como Cadernos de Pesquisa, Contexto e Educação,
Em Aberto, Educação e Sociedade, Educação e Realidade, publicam de uma forma geral artigos na área educacional incluindo a temática da observação. Outros são mais especializados como no caso da Tecnologia Educacional e da Revista Ensaio da Cesgranrio que tem 
publicado muito sobre a questão da avaliação. A Revista Brasileira de Política e Administração da Educação' aparece em sétimo lugar, o que indica talvez uma dispersão do foco de sua produção. Estudo realizado por Pereira (2004) indicou que este periódico enfatizou em suas publicações a Administração Universitária, refletindo a tendência geral da área de privilegiar este nível de ensino, no que converge com o levantamento realizado no Banco de Dados.

Os periódicos que mais contribuíram para o Banco de Dados são publicados na Região Sudeste e Sul. Os 16 periódicos que mais contribuíram para o Banco de Dados estão assim distribuídos: 7 da Região Sudeste, 4 da Região Sul, 3 do Distrito Federal e dois de outros locais, evidenciando mais uma vez o domínio da Região Sudeste e Sul.

\section{Implicações para um Estado do Conhecimento em Administração da Educação}

Este estudo sugere que a Administração da Educação é uma área de conhecimento que tem uma abrangência bastante ampla na medida em que os diferentes tipos de ensino, e de instituições precisam ser administradas. Assim ela consegue ser ao mesmo tempo específica e geral. Ela é específica na medida em que a administração se realiza numa instituição concreta definida por uma série de especificações, nível e tipo de ensino, pública ou privada, urbana ou rural, de área periférica ou central. Ocorrem também processos de ingerência, o que torna ainda mais complexa a análise de um nível sobre o outro.
Podemos comentar inicialmente o número de palavras-chave utilizadas para classificar os artigos na área, foram identificadas cinqüenta e nove palavras-chave. Este número significativo foi sendo produzido como um thesaurus próprio das pesquisadoras emergindo da análise dos títulos e resumos dos artigos publicados em periódicos nacionais. Uma possível interpretação para o elevado número de palavras-chave pode ser uma expressão da riqueza e complexidade da área, pois indica uma série de interfaces com outras áreas do conhecimento. Talvez se assemelhe ao status epistemológico da educação como um todo que se nutre do conhecimento de várias disciplinas, tais como psicologia, neurologia, sociologia, economia, etc., todas contribuindo para a compreensão do fenômeno educacional. $\bigcirc$ status epistemológico da educação seria ao mesmo tempo sua riqueza e sua fragilidade (CASTRO, 1994). Neste sentido (ETGES, 1993, p. 28 apud PEREIRA, 2004), a falta de identidade pode ser uma das dimensões desta fragilidade.

Ficam algumas indagações de natureza teórica. A distribuição das palavras-chave reproduz a estrutura intrínseca da área ou está relacionada ao momento histórico. Em estudo realizado sobre a educação municipal no Estado do Rio Grande do Sul (CASTRO, 2001), foram identificados quatro níveis de interação que possibilitavam uma compreensão do que ocorria na administração da educação municipal. No primeiro nível aparecia a pessoa que exercia a administração da educação municipal, seu repertório, formação e expectativas. No segundo nível revelavam-se as características institucionais da Secretaria Municipal de Educação, sua história, seu desenvolvimen-

1 Consideramos nesta ordem a Revista Brasileira de Administração da Educação e a Revista Brasileira de Política e Administração da Educação como um único periódico, pois ocorreu uma alteração no nome do referido periódico. 
to organizacional, o tamanho da rede. No terceiro nível, surgem as relações entre a Secretaria Municipal de Educação e as outras instituições sociais presentes no município, outras secretarias, a universidade, a comunidade, etc. No quarto nível explicitam-se as relações com o contexto social mais amplo, como a questão da pobreza, da tecnologia, da legislação e da diminuição do papel do Estado. $\bigcirc$ jogo entre estes quatro níveis num processo dinâmico e complexo é que dá forma e permite compreender o processo de administração da educação municipal. Portanto a complexidade e a interatividade entre os diferentes elementos sobrepostos na administração municipal exemplificam a riqueza e dinamicidade da área de administração da educação.

Poderíamos então utilizar a imagem do sistema complexo adaptativo como expressiva e característica da área da Administração da Educação. Uma das características centrais destes sistemas é a interdependência entre o comportamento individual e coletivo (O'DAY, 2002). Os sistemas complexos adaptativos se definem pela população de agentes interativos sejam eles células, pessoas, animais, organizações, escolas ou outros sistemas. Cada um dos quais utiliza um número limitado de estratégias em resposta ao meio ambiente que o circunda e na busca de seus próprios objetivos. A natureza sistêmica deriva dos padrões de interação e da semelhança das estratégias usados pelos agentes.

Vasconcellos (2002, p. 153-154) utiliza a expressão "novo paradigmático" para classificar o cientista que reconhece três dimensões: a complexidade, a instabilidade e a intersubjetividade. Ela incorpora o conceito da intersubjetividade como a inclusão do obser- vador, da auto-referência, na co-construção do conhecimento. Talvez este conceito novoparadigmático seja adequado para pensar a área de administração da educação, considerando a complexidade e instabilidade e que a ação depende da construção do conhecimento na prática dos sujeitos .

Uma outra possível interpretação é que a administração da educação pode ser vista em diferentes planos de segmentação que se sobrepõem numa visão complexa (MATTA, 1987). Tal como a política educacional que se concretiza na escola ou como os diferentes níveis de ação dos secretários a administração da educação pode ser vista como a expressão da política educacional que se concretiza na escola, permitem o englobamento que "é uma operação lógica na qual um elemento é capaz de totalizar o outro em certas situações específicas." (MATTA, 1987, p. 17).

Os conceitos de sistemas complexos adaptativos, os quatro níveis interativos no âmbito da administração da educação municipal (CASTRO, 2000) e os planos de segmentação seriam formas de reconhecer a complexidade e dinamicidade da área de Administração da Educação. $\bigcirc$ número de palavras-chave, as várias interfaces com outras áreas do conhecimento e da prática, a interação de diferentes atores para obtenção de objetivos comuns, sugerem a ausência de uma causalidade linear na área da Administração da Educação.

A necessidade de garantir o funcionamento da escola e das organizações de ensino cria também uma imposição estrutural que impede uma recriação de sentidos e da busca de uma prática que atenda aos objetivos institucionais, locais e sociais da escola, provocando distorções e talvez novas funções. Desta maneira o administrativo não levaria a escola 
ao seu objetivo central a educação, mas as possíveis reações ao contexto cultural e social é que, dinamicamente, lhe dão forma. Werle (1992) comenta com discernimento a permeabilidade e ingerência que ocorrem entre os sistemas de ensino, especialmente entre o nível municipal e estadual. Em muitos aspectos administração do sistema municipal de educação reproduz processos administrativos e burocráticos desenvolvidos em nível estadual.

A mobilização pela carência pode ser um outro fator esclarecedor da produção em Administração da Educação, em vez de pensarmos a escola que queremos, e buscarmos construí-la na prática administrativa, somos mobilizados pela carência e esta condição estrutural impede uma perspectiva profissional de planejamento e construção. As crises do sistema educacional e as constantes buscas de solução através de reformas levam a uma série de intervenções que acenam com uma perspectiva de mudança simplista sem considerar a complexidade das questões de transformação social e organizacional.

\section{Considerações Finais}

Apresentou-se o Banco de Dados "Produção do conhecimento na área de administração da educação: periódicos nacionais, 19822000", e comparou-se o seu desenvolvimento na fase inicial 1982-1994 e na fase final 19952000 e no Banco de Dados como um todo de 1982 a 2000. Os temas que mais se destacaram na fase inicial foram: Administração do Ensino Superior, Administração da Educação e Determinantes do Contexto, Políticas Públicas, Política Educacional, Administração Educacional Escolar, Administração Educacional em nível macro político, Administração e História, Educação e Democratização e Educa- ção Comparada. Na fase final do Banco de Dados, outras temáticas emergiram quais sejam Formação e Desenvolvimento Profissional, Gestão e Cultura, Cidadania, Avaliação da Educação, Ensino Fundamental e Conhecimento e Ação Administrativa. $\bigcirc$ Banco de Dados como um todo reflete as mudanças históricas e os debates que ocorreram no período no contexto educacional brasileiro, mas ao mesmo tempo ele também evidencia alguma estabilidade, pois as palavras-chave Administração do Ensino Superior, Administração da Educação e Determinantes do Contexto, Política Educacional, Políticas Públicas e Administração Educacional Escolar se mantêm entre os dez temas de maior produção independente do período considerado. Desta maneira o Banco de Dados ao mesmo tempo em que reflete o momento histórico vivido, também expressa características estruturais e epistemológicas da área de Administração Educacional, constituindo um estado do conhecimento em Administração da Educação.

Na parte final deste texto refletiu-se acerca das implicações teóricas da classificação da produção em palavras chave e sua distribuição temporal e em periódicos. $\bigcirc$ processo analítico e classificatório de artigos indicou uma abrangência ampla e uma complexidade inerente à área. Administração da educação é ao mesmo tempo específica e geral, permite vários tipos de segmentação e em seus processos interativos se aproxima de sistemas adaptativos complexos. A complexidade e riqueza da área da Administração da Educação se expressa no conceito sistêmico de interação e autoformatação que permite a adaptação à realidade em questão não fazendo uma predição, mas considerando os fatores de instabilidade, complexidade e a intersubjetividade.

Recebido em: 18/01/2005

Aceito para publicação: 17/02/2005. 


\section{ABSTRACT}

\section{State of knowledge in the administration of education: an analyses of the articles published in periodicals 1982 - 2000}

This text presents the Data Bank "Production of Knowledge in the area of Educational Administration 1982-2000: National Periodicals" its objectives, characteristics and analyses it in its integrity. Compare its initial phase 1982-1994 with the final phase 1995-2000 and the totality of the Data Bank from 1982 to 2000. In this Data Bank 3573 articles of national periodicals were classified with a thesaurus of fifty nine key words. Initially the process of classification used the title of the article as a criteria, in the second phase abstracts were included. The key -words with higher frequency in the Data Bank as whole were Administration of Higher Education, Educational Administration and Determinants of the Context, Educational Policy, Public Policy, School Educational Administration, Education and Professional Development, Administration and History, Power, Legislation, Educational Evaluation. In the final part of the text the theoretical implications of the classification of the production in key-words, its temporal distribution and periodicals involved was discussed. It was possible to observe that the analytic and classificatory process indicated a very comprehensive area characterized by complexity. Educational Administration is at the same time specific and general, allows for diferents types of segmentation in its interactive process is close to the complex adaptative systems.

Keywords: Published articles. National periodicals. Educational administration. Data Bank.

\section{RESUMEN}

\section{Estado del Conocimiento en la Administración de la Educación: Un análisis de los artículos publicados en periódicos nacionales 1982-2000}

El texto presenta el Banco de Datos "Producción del Conocimiento en el área de Administración de la Educación 1982-2000 Periódicos Nacionales", sus objetivos y características y lo analiza por completo. Compara su fase inicial 1982-1994 con la fase final 1995-2000. En este Banco están clasificados 3573 artículos de cincuenta y cuatro periódicos nacionales clasificados con un thesaurus de cincuenta y nueve palabras-clave. Inicialmente fueron utilizados los títulos de los artículos para el proceso de clasificación y en la segunda fase fueron incluidos los resúmenes. Las palabras-clave de mayor frecuencia en el Banco fueron Administración de la Enseñanza Superior, Administración de la Educación y Determinantes del Contexto, Política Educacional, Políticas Públicas, Administración Educacional Escolar, Formación y Desenvolvimiento Profesional, Administración e Historia, Poder, Legislación, Evaluación de la Educación. En la parte final del texto abordamos las 
implicaciones teóricas de la clasificación de la producción de palabras-clave, su distribución temporal y en periódicos. Fue posible observar que el proceso de análisis y clasificación de artículos, indicó una gran amplitud y una complejidad relacionada al área. Administración de la Educación es al mismo tiempo específica y general, permite diversos tipos de segmentación y en sus procesos interactivos se aproxima de complejos sistemas de adaptación. Palabras-clave: Artículos publicados. Periódicos nacionales. Administración de la Educación. Banco de Datos.

\section{Referências bibliográficas}

BRZEZINSKI, I.; GARRIDO, E. Análise dos trabalhos do GT Formação de professores : o que revelam as pesquisas no período 1992-1998. Revista Brasileira de Educação, Rio de Janeiro, n. 18, p. 82-100, 2001.

CASTRO, M. L. S. A especificidade do ato pedagógico. In: Simpósio Catarinense de Administração da Educação, 6., 1994, Chapecó, SC. Trabalhos apresentados... Chapecó, SC: AESC, 1994.

CASTRO, M. L. S. Secretário municipal de educação: integrando dados da realidade e da prática. In: Simpósio Luso-Brasileiro de Administração da Educação, 2., 2001, Braga. Trabalhos apresentados... Braga, PT: Universidade de Braga, 2001.

CASTRO, M. L. S.; WERLE, F. O. C. Banco de Dados Produção do Conhecimento na área de Administração da Educação, 1982-2000: periódicos nacionais. Porto Alegre, RS: FAPERGS, PUCRS, 2002. 1 CD-ROM.

Reconstruindo a produção na área de Administração da Educação: 1982-1994: perspectivas temporal e temática em periódicos nacionais. Educação PUCRS, Porto Alegre, 2000.

Temáticas privilegiadas na área de administração da educação: periódicos nacionais, 1982-1994. Cadernos CEDAE, Porto Alegre, n. 5, p. 117-137, 1999.

CATANI, D. B.; FARIA FILHO, L. M. Um lugar de produção e a produção de um lugar: a história e a historiografia divulgadas no GT História da Educação da ANPED (19852000). Revista Brasileira de Educação, Rio de Janeiro, n. 19, p. 113-128, 2002.

FÁVERO, M. L. GT Política de Educação Superior da ANPED: origem desenvolvimento e produção. Revista Brasileira de Educação, Rio de Janeiro, n. 21, p.115-126, 2002.

FERREIRA, N. S. A. As pesquisas denominadas "estado da arte". Educação \& Sociedade, Campinas, SP, v. 23, n. 79, p. 257-272, ago. 2002.

LUNA, S. V. Planejamento de pesquisa: uma introdução. São Paulo: EDUC, 2002. 
MATTA, R. A casa e a rua: espaço, cidadania, mulher e morte no Brasil. Rio de Janeiro: Guanabara, 1987.

NÓBREGA-THERRIEN, S.; THERRIEN, J. O estado da questão: sua compreensão na construção de trabalhos científicos: reflexões teórico-metodológicas. In: Conferência Internacional do Brasil de Pesquisa Qualitativa, 1., 2004. Taubaté, SP. Anais... São Paulo: Cibrapeq, 2004. 1 CD-ROM.

O'DAY, J. A. Complexity, accountability, and school improvement. Harvard Educational Review, Cambridge, Massachusetts, v. 72, n. 3, p. 293-329, Fall 2002.

PEREIRA, G. R. M.; ANDRADE, M. C. L. A construção da administração da educação na RBAE (1983-1996). In: SEMINÁRIO DE PESQUISA EM EDUCAÇÃ̃O DA REGIÃO SUL, 5., 2004, Curitiba. Trabalhos apresentados... Curitiba, PR: ANPED-Sul, 2004. 1 CD-ROM.

VASCONCELOS, M. J. E. Pensamento sistêmico: o novo paradigma da ciência. Campinas, SP: Papirus, 2002.

WERLE, F. O. C. As novas tecnologias e a pesquisa em história da educação. In: FARIA FILHO, L. M. (Org.). Arquivos, fontes e novas tecnologias: questões para a história da educação. Campinas, SP: Autores Associados; Bragança Paulista, SP: Universidade São Francisco, 2000. p. 45-62.

O sistema político administrativo da educação: estudo do relacionamento das instâncias do Estado ao longo da república a partir do município de São Leopoldo. 1993. Tese (Doutorado em Educação)-Faculdade de Educação, Pontifícia Universidade Católica do Rio Grande do Sul, Porto Alegre, 1993.

WERLE, F. O. C.; CASTRO, M. L. S. Abandono escolar: análise temática e temporal da realidade da produção científica brasileira publicada em periódicos. Educação-PUCRS, Porto Alegre, v. 26, n. 50, p. 9-44, 2003.

WERLE, F. O. C.; CASTRO, M. L. S. Administração comparada: uma análise de publicações da América Latina. In: CASTRO, M. L. S.; WERLE, F. O. C. (Org.). Educação comparada na perspectiva da globalização e autonomia. São Leopoldo, RS: Editora Unisinos, 2000.

WITTMANN, L. C.; GRACINDO, R. Ao estado da arte em política e gestão da educação no Brasil. Brasília, DF: ANPAE, 1999.

. Políticas e gestão da educação (1991-1997). Brasília, DF: MEC, Inep, Comped, 2001.

\section{Correspondência:}

flaviaobinowerle@pro.via-rs.com.bf

misson@pucrs.br 